\title{
Monetary Policy Effects on Financial Risk Premia
}

\author{
Paul Söderlind* \\ September 2008 \\ forthcoming in the Manchester School
}

\begin{abstract}
The effect of monetary policy on financial risk premia is analysed in a simple general equilibrium model with sticky wages and an optimising central bank. Analytical results show that equity risk premia and term premia are higher under inflation targeting than under output targeting, and that inflation risk premia are higher for policies that strike a balance between output and inflation stability (and achieve a social optimum) than for policies that target only one of them.
\end{abstract}

Keywords: inflation risk premium, equity risk premium, term premium, announcement effects.

JEL Classification Numbers: E52, E44, G12.

*University of St. Gallen and CEPR. Address: SBF, University of St. Gallen, Rosenbergstrasse 52, CH-9000 St. Gallen, Switzerland. E-mail: Paul.Soderlind@unisg.ch. I thank two anonymous referees for comments. 


\section{Introduction}

This paper uses a simple business cycle model with nominal frictions to analyse how financial risk premia depend on different types of monetary policy. The model is from Bénassy (1995), but extended by money demand shocks and an optimising central bank. This framework generates closed-form solutions (with few parameters) for risk premia and announcement effects, which allows for a simple discussion of the main effects that monetary policy may have on various risk premia.

There is a large literature on both the empirical and theoretical aspects of the link between monetary policy and asset prices. (For a survey of the field, see Sellin (2001).) The contribution of the current paper is to provide simple closed-form solutions for the risk premia. By necessity, this requires the model to be highly stylised-but it shares most main features of current new Keynesian business cycle models. ${ }^{1}$

The most closely related papers are those of Bakshi and Chen (1996) and Boyle and Peterson (1995), which both derive risk premia in monetary business cycle models. Monetary policy is modelled as an exogenous process, possibly correlated with output. The key difference of the current paper is that monetary policy is here systematic in the sense that it minimises a loss function. This allows for a clearer discussion of the relation between policy regimes and asset prices.

The paper is organised as follows: Section 2 summarises the macro model, Section 3 derives optimal monetary policy for different policy preferences, Section 4 studies the risk premia induced by different types of policies, Section 5 shows how monetary policy influences announcement effects and Section 6 concludes.

\section{The Macro Model}

This section summarises the macro model. It relies heavily on Bénassy (1995), but I have added shocks to the money demand equation.

A Cobb-Douglas production function in terms of total factor productivity, $Z_{t}$, capital stock, $K_{t}$, and labour input, $H_{t}$, generates output, $Y_{t}$, according to

$$
Y_{t}=Z_{t} K_{t}^{\alpha} H_{t}^{1-\alpha} \text { with } 0<\alpha<1 .
$$

\footnotetext{
${ }^{1}$ For a more detailed modelling approach, which certainly is more conducive to empirical analysis, see, for instance, Buraschi and Jiltsov (2005).
} 
Competitive firms rent labour and capital from households. Capital accumulation is modelled as

$$
K_{t+1}=A K_{t}^{1-\delta} I_{t}^{\delta} \text { with } 0<\delta<1,
$$

where $I_{t}$ is investment. Hercowitz and Sampson (1991) interpret $\delta$ as the quality of new investment goods relative to old capital. This specification gives a role for capital accumulation in the propagation of shocks, but still delivers a closed-form solution. (With $\delta=1$, new investment goods are so superior that old capital is useless-which also could be thought of as complete depreciation.)

Households choose consumption, $C_{t}$, money holdings, $M_{t}$, and labour supply, $H_{t}$, to maximise expected discounted utility

$$
\mathrm{E}_{0} \sum_{t=0}^{\infty} \beta^{t}\left[\ln C_{t}+\theta_{t} \ln M_{t} / P_{t}+V\left(1-H_{t}\right)\right], \theta_{t}>0,
$$

where $\theta_{t}$ is a preference shifter, $P_{t}$ the current price level, $V$ is a concave function and labour endowment is normalized to unity. The additivity and logarithmic specification are important for getting a closed form solution. Households spend on consumption, acquiring real money balances and investments. The budget restriction

$$
C_{t}+M_{t} / P_{t}+I_{t}=H_{t} W_{t} / P_{t}+\Gamma_{t} K_{t}+\mu_{t} M_{t-1} / P_{t}
$$

says that the spending must equal the sum of real wage earnings ( $W_{t}$ is the nominal wage rate), rental income from capital, and the real value of cash brought over from the previous period. The capital income is the rental rate times the capital stock, $\Gamma_{t} K_{t}$. A simplifying assumption in Bénassy's model is that cash brought over from $t-1$ carries a kind of interest rate $\left(\mu_{t} \neq 1\right)$ whereby the "seigniorage" is paid back to the cash holders: money supply is $M_{t}=\mu_{t} M_{t-1}$. The aggregate resource constraint is that output equals consumption plus investment. In equilibrium, firms make zero profits. (We could add the value of installed capital, $q_{t} K_{t}$, to the right hand side of the budget constraint, and the value of purchased "old" capital to the left hand side—but in equilibrium these terms cancel.)

Nominal wage contracts are written one period in advance: the log nominal wage is set equal to the expected log nominal marginal product of labour-and households are obliged to satisfy (supply) any labour demand at the realized real wage.

Let lowercase letters denote logs and assume that log productivity (the Solow residual) 
is a stationary $\mathrm{AR}(1)$ process

$$
z_{t}=\rho z_{t-1}+\varepsilon_{t}, \text { where } \varepsilon_{t} \text { is iid and } 0 \leq \rho<1 .
$$

This type of process is extensively used in the RBC literature and implies persistence of productivity. For instance, Cooley and Prescott (1995) estimate the autocorrelation to be above 0.9 in US quarterly data.

For notational simplicity, let $\psi_{t}$ be the (log) money demand shifter (which equals the logarithm of the discounted sum of expected future preference shifters, $\left.\ln \left(\sum_{s=0}^{\infty} \beta^{s} \mathrm{E}_{t} \theta_{t+s}\right)\right)$, and let $u_{t}^{\psi}$ be the surprise ("money demand shock")

$$
\psi_{t}=\mathrm{E}_{t-1} \psi_{t}+u_{t}^{\psi}
$$

Similarly, let $u_{t}^{m}$ be the surprise in log money supply

$$
m_{t}=\mathrm{E}_{t-1} m_{t}+u_{t}^{m}
$$

Solving the model gives the following key features (see Appendix A for details and references). First, log consumption equals output plus a constant and the same holds for log investment (constants suppressed)

$$
\begin{aligned}
c_{t} & =y_{t}, \\
i_{t} & =y_{t} .
\end{aligned}
$$

Second, a velocity equation holds with the money demand shifter playing the role of velocity,

$$
m_{t}-p_{t}-c_{t}=\psi_{t}
$$

Third, labour demand is (constant suppressed) a function of the money market surprise

$$
h_{t}=u_{t}^{m}-u_{t}^{\psi}
$$

so monetary policy can affect the real side of the economy (by creating a surprise inflation).

By combining these results with the model equations, we can write the dynamics of 
output as (a constant is suppressed)

$$
\begin{aligned}
y_{t} & =\mathrm{E}_{t-1} y_{t}+(1-\alpha)\left(u_{t}^{m}-u_{t}^{\psi}\right)+\varepsilon_{t}, \text { with } \\
\mathrm{E}_{t-1} y_{t} & =(\rho+\delta-1) z_{t-1}+(1-\delta+\delta \alpha) y_{t-1}-(1-\delta)(1-\alpha)\left(u_{t-1}^{m}-u_{t-1}^{\psi}\right),
\end{aligned}
$$

and inflation as

$$
\begin{aligned}
\pi_{t} & =\mathrm{E}_{t-1} \pi_{t}+\alpha\left(u_{t}^{m}-u_{t}^{\psi}\right)-\varepsilon_{t}, \text { with } \\
\mathrm{E}_{t-1} \pi_{t} & =\left(\mathrm{E}_{t-1} m_{t}-m_{t-1}\right)-\left(\mathrm{E}_{t-1} y_{t}-y_{t-1}\right)-\left(\mathrm{E}_{t-1} \psi_{t}-\psi_{t-1}\right) .
\end{aligned}
$$

The great advantage of this model is that the dynamic equilibrium is log-linear. This is the key to obtain analytical results for optimal policy and risk premia, without having to resort to approximations.

The first lines of (12) and (13) emphasize the innovations in period $t$, which will be the determinants of the risk premia. These expressions show that the model shares a number of key short-run properties with other new Keynesian models: (i) money demand shocks move inflation and output in the same direction; (ii) productivity (supply) shocks move them in different directions; and (iii) monetary policy has an effect on both output and inflation.

\section{Monetary Policy Rules}

This section summarises several possible monetary policy rules. All policy rules considered here are commitment rules, and there is no issue of inflation bias. The rules are of the form

$$
m_{t}=\mathrm{E}_{t-1} m_{t}+u_{t}^{m}, \text { where } u_{t}^{m}=\gamma u_{t}^{\psi}+v \varepsilon_{t},
$$

where the specification of $\mathrm{E}_{t-1} m_{t}$ as well as the values of $\gamma$ and $v$ may differ across the rules. This type of rule does not allow for any exogenous monetary policy shocks (typically part of most macroeconomic models, see, for instance, Thorbecke (1997)). That is not restrictive, since in this model (and most others), a monetary policy shock is precisely the same as a (negative) money demand shock. We can therefore apply two different interpretations to the latter-and instead focus on the systematic policy.

A passive policy keeps the money supply constant. This means that all money supply terms $\left(u_{t}^{m}, \mathrm{E}_{t-1} m_{t}\right.$ and $\left.m_{t-1}\right)$ drop out from the dynamics of output and inflation. 
A standard textbook monetary policy minimises a loss function in terms of the variances of output and inflation ${ }^{2}$

$$
L=\lambda \operatorname{Var}\left(y_{t}\right)+(1-\lambda) \operatorname{Var}\left(\pi_{t}\right)
$$

where $\lambda \geq 0$ is the weight on output stabilisation and $1-\lambda$ on inflation. We can split up the variance as $\operatorname{Var}\left(y_{t}\right)=\operatorname{Var}\left(y_{t}-\mathrm{E}_{t-1} y_{t}\right)+\operatorname{Var}\left(\mathrm{E}_{t-1} y_{t}\right)$ and similarly for inflation. We then generalize the loss function by allowing the two output components to have different weights

$$
\begin{array}{r}
L=\lambda\left[\operatorname{Var}\left(y_{t}-\mathrm{E}_{t-1} y_{t}\right)+\chi \operatorname{Var}\left(\mathrm{E}_{t-1} y_{t}\right)\right]+ \\
(1-\lambda)\left[\operatorname{Var}\left(\pi_{t}-\mathrm{E}_{t-1} \pi_{t}\right)+\operatorname{Var}\left(\mathrm{E}_{t-1} \pi_{t}\right)\right],
\end{array}
$$

where $\chi \geq 0$ is the relative weight on expected output (relative to output surprises). I will consider the cases of $\chi=1$ and $\chi=0$.

We can directly observe that minimizing this loss function will give a policy rule that accommodates the money demand shock $(\gamma=1$ in (14)), since that shock drives output and inflation in the same direction (see (12) and (13)).

It is also immediate that the predictable part of the policy rule $\left(\mathrm{E}_{t-1} m_{t}\right.$ in (14)) can be designed to make expected inflation constant. This follows from the fact that predictable money supply does not affect output and (by definition) cannot affect the inflation surprise. This means that the predictable part of the policy rule (14) is on the form

$$
\mathrm{E}_{t-1} m_{t}=m_{t-1}+\left(\mathrm{E}_{t-1} y_{t}-y_{t-1}\right)+\left(\mathrm{E}_{t-1} \psi_{t}-\psi_{t-1}\right)
$$

It is clear from (13) that this rule makes expected inflation zero: expected money supply growth equals expected money demand growth at unchanged prices-see the velocity equation (10). ${ }^{3}$

The response of monetary policy to productivity shocks ( $v$ in (14)) is therefore chosen to minimize remaining terms of the loss function (16). With inflation targeting $(\lambda=0)$ we get

$$
v=1 / \alpha
$$

which is positive ( $\alpha$ is the capital share of output) — this is a pro-cyclical policy. It is

\footnotetext{
${ }^{2}$ See West (1986) for a comparison of targeting output or the output gap.

${ }^{3}$ Equation (12) shows how to express expected output growth in terms of the state variables.
} 
immediate from (13) that this completely stabilises inflation surprises. The basic intuition is that a productivity shock increases money demand (by increasing output), so a money injection is necessary to restore money market equilibrium (at unchanged prices). Alternatively, with output surprise targeting $(\lambda=1, \chi=0)$

$$
v=-1 /(1-\alpha)
$$

which is negative - this is a counter-cyclical policy. It is clear from (12) that this stabilises output surprises: a positive productivity shock is met by a contractionary monetary policy, which increases the real wage and reduces labour demand.

With output targeting where output surprises and expected output carry equal weights $(\lambda=1, \chi=1)$, the policy parameter is more complicated. However, as long as the productivity shock has a non-negative autocorrelation $(\rho \geq 0)$, we can establish that (19) is the upper boundary. ${ }^{4}$ Output stabilisation is more counter-cyclical (than output surprise targeting) since it tries to bring investment down to counter a persistent boom (driven by high investments and persistent productivity).

Trading off inflation and output surprise variability $(0 \leq \lambda \leq 1, \chi=0)$ gives

$$
v=\frac{\alpha-\lambda}{\lambda(1-\alpha)^{2}+(1-\lambda) \alpha^{2}} .
$$

(See Appendix A for a short derivation.) The sign of the reaction to a productivity shock depends on the weight $\lambda$ : it turns negative (counter-cyclical policy) whenever output surprise stabilisation is important enough $(\lambda>\alpha)$. It is straightforward to show that (18) and (19) are special cases and that $v$ is monotonically decreasing in $\lambda$.

Trading off inflation and output variability $(0 \leq \lambda \leq 1, \chi=1)$ gives a slightly messy expression-which is therefore given in Appendix A. However, the result is similar to (20). A numerical example is given in Figure 1: the calibration of the parameters imply autocorrelated productivity, a reasonable capital share of output and slow depreciation. Subfigure a illustrates that inflation is stabilised at a positive value of $v$, while both output and output surprises are stabilised at (fairly similar) negative values of $v$. Subfigure $b$ illustrates how the optimal value of $v$ depends on $\lambda$, when the loss function includes either output $(\chi=1)$ or output surprises $(\chi=0)$. The figure reiterates the earlier

\footnotetext{
${ }^{4}$ In the very special case of complete capital depreciation, $\delta=1$ and zero autocorrelation of productivity, $\rho=0$, we reach this upper boundary.
} 
findings (inflation targeting gives a positive coefficient et vice versa), but it also suggests that output and output surprise considerations give fairly similar policies. A numerical grid search over the allowed parameter space (not reported) confirms this impression.
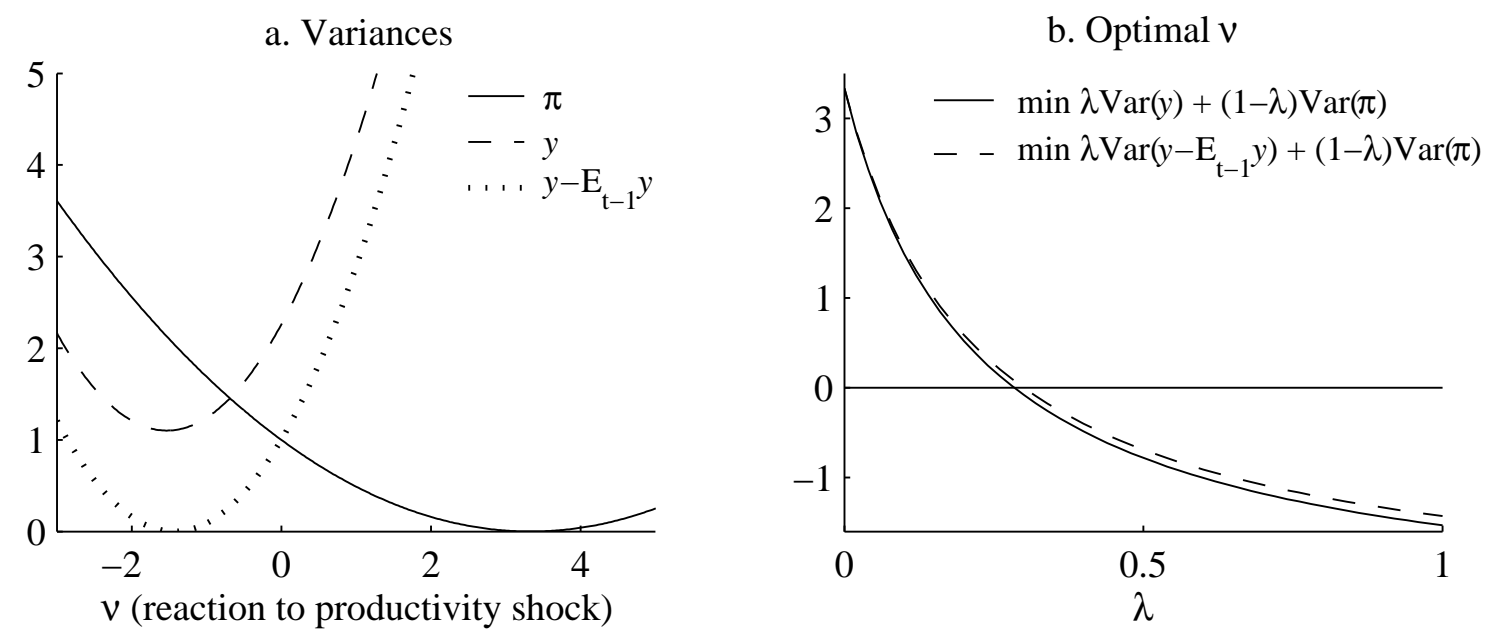

Figure 1: Optimal reaction to a productivity shock This figure shows numerical results based on $\rho=0.7, \alpha=0.3, \delta=0.1$.

At intermediate policy preferences (in terms of $\lambda$ ), the optimal $v$ is zero: in (20) this happens at $\lambda=\alpha$. This policy can also be motivated as a social optimum. The reason is that a policy that accommodates money demand shocks, but does not react to productivity shocks ( $\gamma=1$ and $v=0$ in (14)) will undo the only imperfection: sticky nominal wages. This is socially beneficial from a utility-based perspective (see Woodford (2002) for an extensive discussion of "Ramsey policies" in monetary policy models). In a flexible-price equilibrium (no pre-contracted wages), labour demand is constant over time, but with sticky wages labour demand equals $h_{t}=u_{t}^{m}-u_{t}^{\psi}$. By increasing the money supply in response to money demand shocks (and thus accommodating the shock), the policy stops any surprises to the nominal marginal product of labour. ${ }^{5}$

To summarise, all the different optimal policies would accommodate the money demand shocks (or alternatively, not generate any policy shocks). Once that is done, we can think of three different types of responses to a productivity shock: a pro-cyclical response

\footnotetext{
${ }^{5}$ Productivity shocks do not affect the nominal marginal product of labour, since they increase output as much as they decrease the price level.
} 
(inflation targeting, $v>0$ ), no response (social optimum, $v=0$ ) and a counter-cyclical response (output or output surprise targeting, $v<0$ ).

\section{Risk Premia}

This section analyses how risk premia (the expected return in excess of a riskfree return) on various assets depend on monetary policy. The focus is on three different risk premia: the inflation risk premium on nominal interest rates, the risk premium on a long-lived consumption claim (the "equity risk premium") and the term premia in the yield curve. ${ }^{6}$

Although these assets do not show up in the budget restriction, adding them would not change the equilibrium (markets are already complete). Adding them and deriving the first order conditions shows that any gross real return $\left(R_{t+1}\right)$ must satisfy

$$
\mathrm{E}_{t}\left[\beta\left(C_{t} / C_{t+1}\right) R_{t+1}\right]=1 .
$$

To get simple expressions, I assume that the shocks in the model are normally distributed and that they are uncorrelated. Evaluating (21) for a risky asset and then for a riskfree asset (with gross return $R_{f t}$ ) and combining gives the risk premium ${ }^{7}$

$$
R P=\ln \left(\mathrm{E}_{t} R_{t+1} / R_{f t}\right)=\operatorname{Cov}_{t}\left(\Delta c_{t+1}, r_{t+1}\right),
$$

where $\Delta c_{t+1}$ denotes the consumption growth $\left(c_{t+1}-c_{t}\right)$ and $r_{t+1}$ the log real return ( $\left.\ln R_{t+1}\right)$. (See Appendix B for details on the derivation.)

\subsection{The Inflation Risk Premium on a Nominal Bond}

The (modern) Fisher equation says that a nominal interest rate equals the sum of three components: the real interest rate, expected inflation and an inflation risk premium. This risk premium is the expected real return on a nominal bond-in excess of the return on a real bond (the riskfree asset). The reason for the risk premium is that future inflation is uncertain, which carries over to the real (ex post) return on the nominal bond.

\footnotetext{
${ }^{6}$ The analysis is done in a framework where the policy rule is constant and all shocks have constant volatilities. Both assumptions can be relaxed without changing the structure of the equilibrium.

${ }^{7}$ The alternative definition of the risk premium, $\mathrm{E}_{t}\left(r_{t+1}-\ln R_{f t}\right)$ is the same, except for a Jensen's inequality term.
} 
A one-period nominal bond pay one unit of currency in $t+1$ and has a current nominal price of $B_{t}$ (which we don't have to determine explicitly - at least not for the purpose of understanding risk premia). The nominal gross return is therefore $1 / B_{t}$, so the real gross return is $R_{t+1}=\left(1 / B_{t}\right) /\left(P_{t+1} / P_{t}\right)$, where $P_{t}$ is the general price level. That is, log real return equals the deflation minus the $\log$ bond price

$$
r_{t+1}=-\pi_{t+1}-\ln B_{t}
$$

By using in (22), the (inflation) risk premium (denoted $R P^{\pi}$ ) of a one-period nominal bond is

$$
\begin{aligned}
R P^{\pi} & =\operatorname{Cov}_{t}\left(\Delta c_{t+1},-\pi_{t+1}-\ln B_{t}\right) \\
& =\operatorname{Cov}_{t}\left(\Delta c_{t+1},-\pi_{t+1}\right),
\end{aligned}
$$

where the second equality comes from the fact that adding/subtracting variables known in $t$ does not change the conditional covariance. This is the conditional covariance of consumption growth and future deflation. If this covariance is positive, then the real return on the bond tends to be low (inflation is high) at the wrong times, that is, when consumption is scarce (marginal utility is high).

We first look at the case with money demand shocks only and passive policy. From (8) and (12)-(13) we immediately get

$$
R P^{\pi}=-(1-\alpha) \alpha \sigma_{\psi}^{2},
$$

where $\sigma_{\psi}^{2}$ is the variance of the money demand shock. This inflation risk premium is clearly negative (since $0<\alpha<1$ ). Money demand shocks move inflation and output in the same direction, so the real return of nominal bonds is high when consumption is low: a nominal bond is then better than a safe (in real terms) asset. An active monetary policy that accommodates the money demand shocks (effectively making them disappear) therefore increases the inflation risk premium.

We now study the case of productivity shocks. With the policy rule (14) that accommodates the money demand shocks and reacts to productivity shocks with the coefficient $v$, the model gives

$$
R P^{\pi}=-[(1-\alpha) v+1](\alpha \nu-1) \sigma_{\varepsilon}^{2},
$$

where $\sigma_{\varepsilon}^{2}$ is the variance of the productivity shocks. Figure 2.a gives an illustration by 
plotting the inflation risk premium against the coefficient $v$ : the inflation risk premium shows an inverted $U$-shape. Indeed, the risk premium is zero at both strict inflation targeting $\left(v=1 / \alpha\right.$, indicated by a vertical dotted line and the symbol $\left.v_{\pi}\right)$ and output surprise targeting $\left(v=-1 /(1-\alpha)\right.$, indicated by a vertical dotted line and the symbol $\left.v_{y-E} y\right)$. If either output or inflation surprises are zero, then the real return on the nominal bond is considered to be riskfree. The case of output targeting is typically very similar to output surprise targeting.
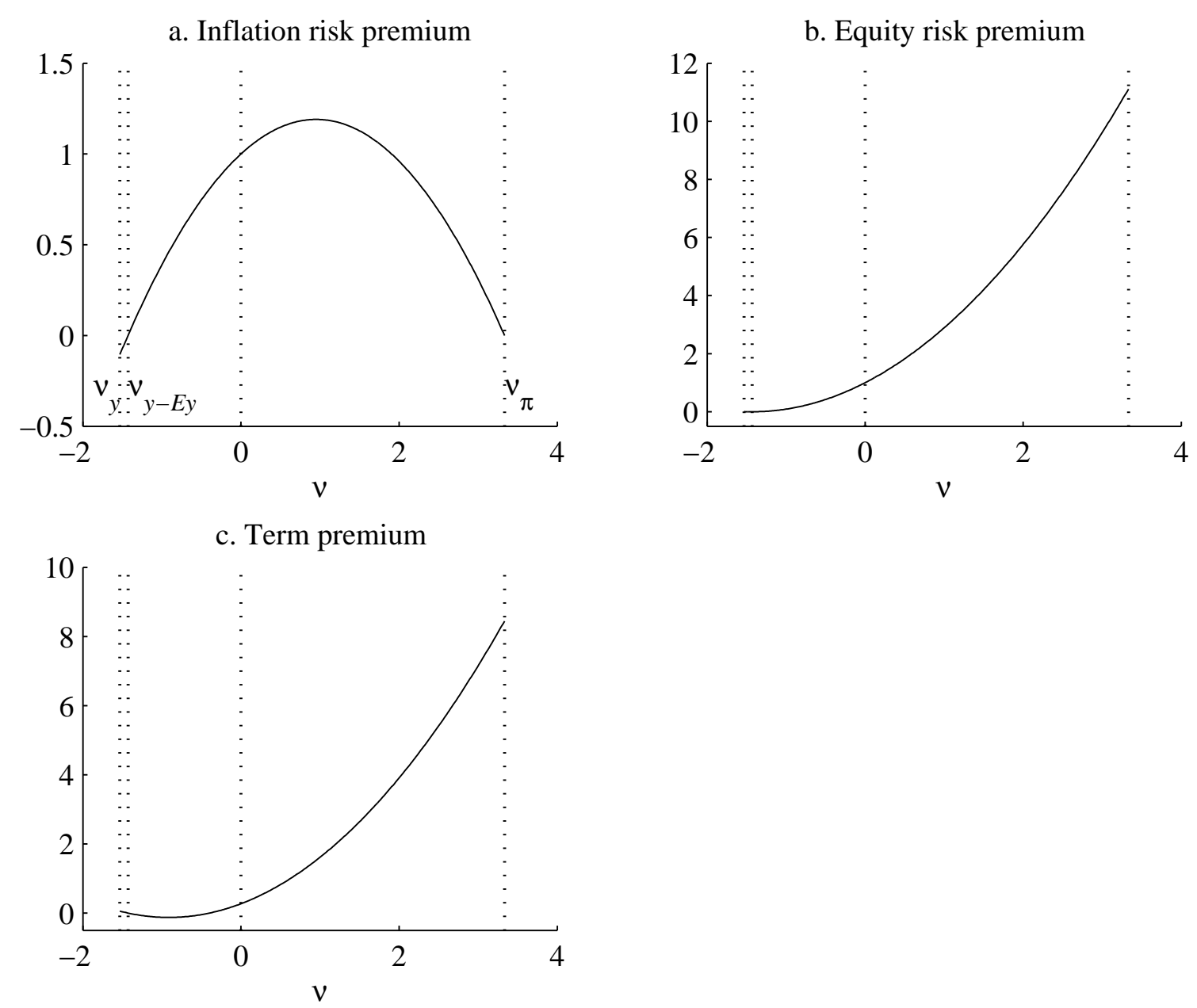

Figure 2: Risk premia as a function of the policy reaction to productivity shocks, $v$. This figure shows numerical results based on $\rho=0.7, \alpha=0.3, \delta=0.1$. Money demand shocks are assumed to be accommodated. The vertical lines indicate the locations of the following policies: minimise the variance of output $\left(v_{y}\right)$, minimise the variance of output surprises $\left(v_{y-E y}\right)$, passive policy $(0)$, and minimise the variance of inflation $\left(v_{\pi}\right)$. 
In the intermediate case of no reaction to the productivity shock $(v=0)$ which corresponds to a social optimum, the risk premium equals $\sigma_{\varepsilon}^{2}$, which is clearly positive. The intuition is that productivity shocks move inflation and output in different directions, so the real return on a nominal bond is low at the same time as consumption is low-this is a risky asset. This feature is shared by all policies from balanced preferences (intermediate values of $\lambda$ ), since such policies are not sufficiently aggressive to either stabilise inflation or output.

To summarise the findings on the inflation risk premium, $(i)$ accommodating money demand shocks increases the risk premium; (ii) strict inflation or strict output targeting generates low risk premia, while more balanced preferences give higher risk premia.

\subsection{The Risk Premium on a Consumption Claim}

A claim on (a given fraction of) next period's aggregate consumption (or output) is an interesting proxy for equity in models where firms make no profits. The reason for a risk premium is that the future consumption is uncertain.

The gross return on a one-period consumption claim is $R_{t+1}=C_{t+1} / B_{t}$, where $B_{t}$ is its price in period $t$. (I am recycling notation here.) The log return is therefore

$$
r_{t+1}=c_{t+1}-\ln B_{t}
$$

By using in (22), the risk premium (expected real return in excess of the return on a real bond, denoted $R P^{c}$ ) of a claim on next period's consumption (the "equity premium") is

$$
\begin{aligned}
R P^{c} & =\operatorname{Cov}_{t}\left(\Delta c_{t+1}, c_{t+1}-\ln B_{t}\right) \\
& =\operatorname{Var}_{t}\left(\Delta c_{t+1}\right) .
\end{aligned}
$$

The risk premium is therefore the conditional variance of consumption growth, which is clearly non-negative. It is straightforward to demonstrate that a perpetual claim on the (infinite) future stream of aggregate consumption has the same risk premium (see Appendix B).

The intuition is that the next period's payoff (the "dividend") is proportional to the consumption level, which is perfectly negatively correlated with marginal utility. This makes the consumption claim the most risky asset possible (per unit of volatility). It therefore provides an interesting boundary for the risk premium on equity (this is yet 
another version of the Hansen and Jagannathan (1991) bound).

With money demand shocks only and passive policy, the risk premium (from (8) and (12)) is

$$
R P^{c}=(1-\alpha)^{2} \sigma_{\psi}^{2},
$$

which is positive. Money demand shocks contribute to output surprises by affecting the price level and thereby the real wage - and thus make consumption claims risky. A policy that accommodates the money demand shocks contributes to reducing the premium.

With the policy rule (14) that accommodates the money demand shocks and reacts to productivity shocks with the coefficient $v$, the model gives

$$
R P^{c}=[(1-\alpha) v+1]^{2} \sigma_{\varepsilon}^{2},
$$

which is non-negative. See Figure $2 . \mathrm{b}$ for an illustration. The risk premium is zero at output surprise targeting $(v=-1 /(1-\alpha))$ and then increasing in the reaction coefficient $v$. For instance, with no reaction to productivity shocks $(v=0)$ the risk premium is positive $\left(\sigma_{\varepsilon}^{2}\right)$ and at inflation targeting $(v=1 / \alpha)$ it is even higher $\left(\sigma_{\varepsilon}^{2} / \alpha^{2}\right)$. The intuition is that a strong policy preference for output stability will buffer most of the output surprises-and thereby reduce the risk premium on a consumption claim. A policy aimed at inflation stability will do just the opposite.

To summarise the findings on the risk premia of a consumption claim, $(i)$ accommodating money demand shocks decreases the risk premium; (ii) strict output targeting also reduces the risk premium, while preferences towards inflation stabilisation increase it.

\subsection{The Term Premium of a Real Bond}

The risk premium (term premium) on a long real bond is the expected real return (over one period) on a long real bond-in excess of the of the return on a one-period real bond. The reason for the term premium is that the future price of a long bond is uncertain. If the term premium is positive, then the real yield curve will (on average) slope upwards. To keep the expressions tractable, the focus here is on a two-period bond.

Consider a real bond that pays one unit of the consumption good in $t+2$. The gross return in $t+2$ is $R_{t+2}=1 / B_{t+1}^{(1)}$, where $B_{t+1}^{(1)}$ is the price of this bond in $t+1$. (I am once again recycling notation here.) Using this return in (21), but with all time subscripts 
advanced one period, gives the bond price as

$$
\begin{aligned}
B_{t+1}^{(1)} & =\mathrm{E}_{t+1} \beta\left(C_{t+1} / C_{t+2}\right) \\
& =\beta \exp \left[-\mathrm{E}_{t+1} \Delta c_{t+2}+\operatorname{Var}_{t+1}\left(\Delta c_{t+2}\right) / 2\right],
\end{aligned}
$$

where the second lines relies on the assumption that shocks are normally distributed (which carries over to all $\log$ variables). You may buy this bond already in $t$ (it is then a two-period bond), at the price $B_{t}^{(2)}$. The gross return from holding it until $t+1$ is $R_{t+1}=B_{t+1}^{(1)} / B_{t}^{(2)}$, so the $\log$ return is

$$
r_{t+1}=\ln \beta-\mathrm{E}_{t+1} \Delta c_{t+2}+\operatorname{Var}_{t+1}\left(\Delta c_{t+2}\right) / 2-\ln B_{t}^{(2)} .
$$

By using in (22), the risk premium (denoted $R P^{T}$ ) on a two-period real bond is

$$
\begin{aligned}
R P^{T} & =\operatorname{Cov}_{t}\left(\Delta c_{t+1}, \ln \beta-\mathrm{E}_{t+1} \Delta c_{t+2}+\operatorname{Var}_{t+1}\left(\Delta c_{t+2}\right) / 2-\ln B_{t}^{(2)}\right) \\
& =-\operatorname{Cov}_{t}\left(\Delta c_{t+1}, \Delta c_{t+2}\right),
\end{aligned}
$$

where the second equality comes from the facts $(a)$ the conditional variance is constant; (b) variables known $t$ or constant do not enter the conditional covariance; $(c)$ $\operatorname{Cov}_{t}\left(\Delta c_{t+1}, \mathrm{E}_{t+1} \Delta c_{t+2}\right)$ equals $\operatorname{Cov}_{t}\left(\Delta c_{t+1}, \Delta c_{t+2}\right)$ since the expectation error cannot be correlated with any earlier information.

This real term premium is the negative of the conditional autocovariance of consumption growth. The intuition is that a long real bond gives a capital loss in $t+1$ if $\mathrm{E}_{t+1}\left(\Delta c_{t+2}\right)$ is high (investors then want to save less for $t+2$, making the real bond less attractive). If this typically happens when consumption is scarce in $t+1$ (negative autocorrelation), then the long real bond is considered risky.

With money demand shocks only and passive policy, (8) and (12) give the term premium as

$$
R P^{T}=(1-\delta \alpha) R P^{c}
$$

(See Appendix B for details on the derivation). The term premium is here proportional to the risk premium on a consumption claim (29)—and thus positive (since both $\alpha$ and $\delta$ are between zero and one). The basic mechanism is that a money demand shock in $t+1$ drives down output. Due to the drop in capital accumulation, this will also have a negative effect on the expected output in $t+2$, but to a smaller extent. Investors will thus have 
small incentives to save in $t+1$, so bond prices drop: a capital loss when consumption is scarce. A policy that accommodates the money demand shocks therefore contributes to flatting the yield curve (on average).

With the policy rule (14) that accommodates the money demand shocks and reacts to productivity shocks with the coefficient $v$, the model gives

$$
R P^{T}=\left[1-\delta \alpha-\frac{\rho}{(1-\alpha) \nu+1}\right] R P^{c},
$$

which is typically also very similar to the risk premium on the consumption claim (now (30)). The basic mechanism is the same as with the money demand shocks, even if output is now driven by productivity shocks. See Figure 2.c for an illustration. In particular, at output surprise targeting $(v=-1 /(1-\alpha))$ the term premium is zero, and at inflation targeting the term premium is likely to be positive: it is $\delta \alpha-1+\rho$ times the conditional variance of consumption (which equals $R P^{c}$ ) which is positive for all plausible values of the capital share of output $\alpha$ (typically estimated to be below 0.4, see Cooley and Prescott (1995)).

To summarise the findings on the real term premium, $(i)$ accommodating the money demand shocks contributes to flatting the yield curve and (ii) output targeting also flattens the yield curve, while inflation targeting most likely does the opposite.

\section{The Reaction of Asset Prices to News}

This section briefly analyses how the reaction of asset prices to news is affected by the monetary policy. "News" are here represented by surprise shocks to productivity and money demand. ${ }^{8}$

I first consider the policy rule (14) that accommodates the money demand shocks and reacts to productivity shocks with the coefficient $v$. The focus is on three asset "prices": a short real interest rate, a long real interest rate and the price of a consumption claim (as a proxy for equity). ${ }^{9}$ It is straightforward to show (use (8), (12), (14) and (21), see

\footnotetext{
${ }^{8}$ In practice these shocks are not observed directly: we instead observe news about employment, orders, etc. These are functions of the underlying shocks. In most equilibrium models those functions depend themselves on the policy regime, so the mapping to empirical studies is not straightforward.

${ }^{9}$ The reaction of nominal bonds is virtually the same as the reaction of real bonds, since all policy rule considered here make expected inflation zero.
} 
Appendix B) that the reactions to a productivity shock are

$$
\begin{array}{ll}
\text { Short real interest rate } & \rho-(1-\delta \alpha)[1+(1-\alpha) \nu] \\
\text { Two-period real interest rate } & \rho(\rho+\alpha \delta) / 2+\{[1-\delta(1-\alpha)] \delta \alpha-1\}[1+(1-\alpha) v] / 2 \\
\text { Log price consumption claim } & (1-\alpha) v+1
\end{array}
$$

Since this is a linear model, the effects are unchanged across time and business cycle conditions (see Andersen, Bollerslev, Diebold, and Vega (2007) for empirical evidence of the contrary).

To develop some intuition for these expressions, consider output surprise targeting $(v=-1 /(1-\alpha))$. The reactions to a productivity shock are then

$\begin{array}{ll}\text { Short real interest rate } & \rho \\ \text { Two-period real interest rate } & \rho(\rho+\alpha \delta) / 2 \\ \text { Log price consumption claim } & 0\end{array}$

In this case, both interest rates increase in response to a productivity shock, but the long rate less so (since $\rho+\alpha \delta<2$ as all the parameters are less than one). The reason is that the (persistent) productivity shock will increase future output and consumption. However, the counter-cyclical monetary policy effectively keeps current output and consumption unchanged. This means that the expected consumption path is upward sloping, making savings unattractive (lowering bond prices, raising interest rates). The long rate reacts less than the short rate, so the yield curve will slope downward.

A similar effect also tends to make the consumption claim less attractive-but this is compensated by the fact that the future high productivity will make the consumption claim "dividends" higher than without the shock: the final effect (at output surprise targeting) is to keep the price of the claim unchanged.

Figure 3 gives a numerical illustration of what other policies imply by plotting the reaction against the coefficient $v$. (Output surprise targeting is at the vertical dotted line marked by $v_{y-\mathrm{E} y}$.) The response of both interest rates becomes lower and lower as policy becomes more pro-cyclical (the derivatives with respect to $v$ of the effects on the interest rates in (36) are negative for all permissible parameter values). With sufficiently procyclical policy (for instance, inflation targeting located at the vertical dotted line marked 


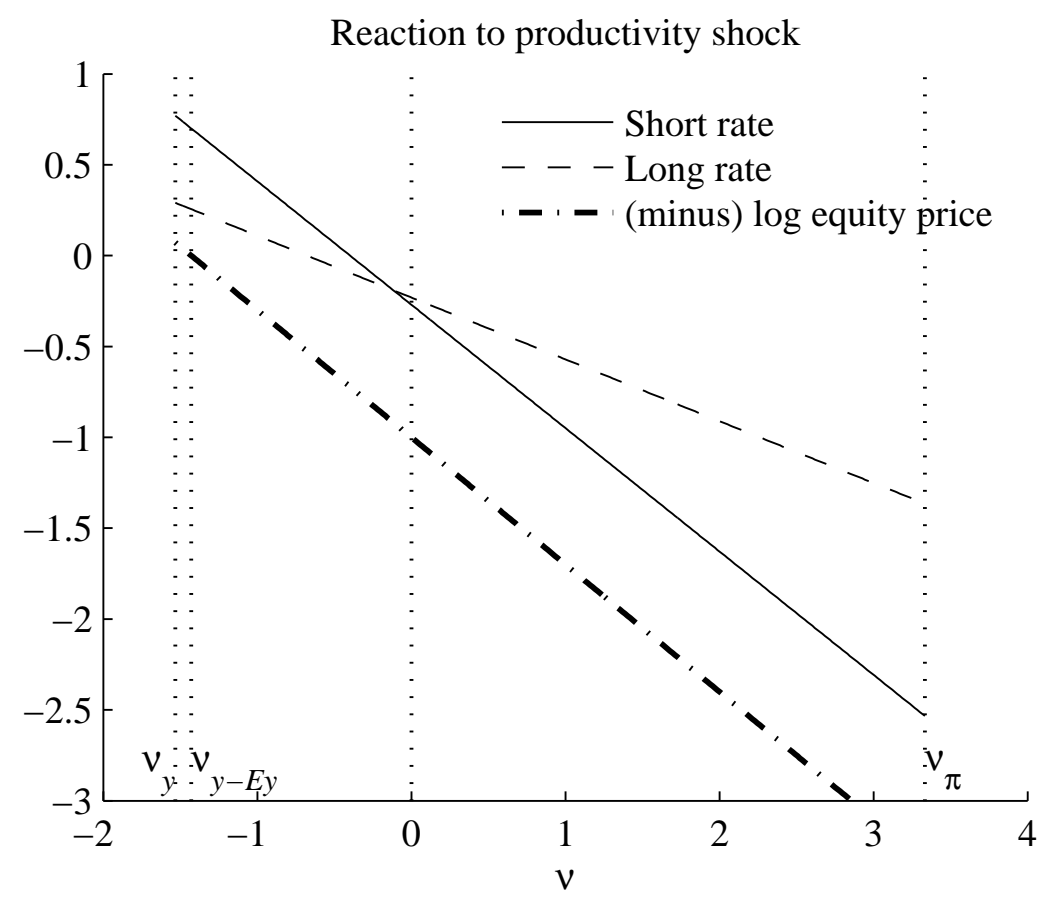

Figure 3: Asset price reaction to a productivity shock, plotted as a function of the policy reaction to productivity shocks, $\boldsymbol{v}$. This figure shows numerical results based on the same assumptions as in Figure 2. The vertical lines indicate the locations of the following policies: minimise the variance of output $\left(v_{y}\right)$, minimise the variance of output surprises $\left(v_{y-E y}\right)$, passive policy $(0)$, and minimise the variance of inflation $\left(v_{\pi}\right)$.

by $v_{\pi}$ ), the interest rate response is negative. The reason is that the expected consumption path is then downward sloping, making saving attractive (driving up prices of bonds and consumption claims). As before, the long rates reacts less, so the yield curve will slope upward. Similarly, for the consumption claim: saving is attractive, especially in an asset that will pay high "dividends" in the future (the derivatives with respect to $v$ of the effects on the consumption claim in (36) is positive). (To facilitate comparison with the interest rates, which are the negative of the bond prices, Figure 3 plots the negative of the log consumption claim price.)

A negative money demand shock can be thought of as a positive aggregate demand 
shock (see (12)). The reactions to a negative money demand shock are

$$
\begin{array}{ll}
\text { Short real interest rate } & -(1-\delta \alpha)(1-\alpha) \\
\text { Two-period real interest rate } & -\{1-[1-\delta(1-\alpha)] \delta \alpha\}(1-\alpha) \\
\text { Log price consumption claim } & 1-\alpha
\end{array}
$$

It is intuitively clear that the response (of asset prices) to an aggregate demand shock is similar to the case of a productivity shock met by pro-cyclical policy (for instance, inflation targeting). Both cases generate a downward-sloping expected consumption path and thereby make saving attractive (driving up prices of bonds and consumption claims). Accommodating the money demand shocks clearly means that these movements disappear.

To summarise the findings on the reaction to news, $(i)$ productivity shocks that are met by counter-cyclical policy (output surprise targeting) will raise interest rates, but short rates more than long rates; (ii) productivity shocks that are met by pro-cyclical policy (inflation targeting) will lower interest rates and make equity more expensive; and (iii) aggregate demand shocks (negative money demand shocks) give reactions similar to case (ii).

\section{Conclusion}

This paper uses a simple monetary business cycle model with optimal monetary policy to arrive at closed-form expressions for three different types of financial risk premia: the inflation risk premium on nominal bonds, the equity risk premium and the term premium on long bonds.

There are two main results of the paper. First, policies that aim at stabilising money demand shocks are likely to increase the inflation risk premium (of nominal bonds), but decrease the equity premium and the term premium (of long real bonds). Second, in the face of supply shocks, the effects depend crucially on whether the policy targets output stability, inflation stability or a social optimum: output targeting is likely to decrease all risk premia, inflation targeting is likely to increase risk premia on real assets and decrease them on nominal assets, while the socially optimal policy has the side effect of generating a high inflation risk premium. 


\section{A Model Appendix}

This appendix gives some details on the equilibrium dynamics of the model. All the first order conditions, except for real money balances, are the same as in Bénassy (1995).

Combining the first order conditions gives the money demand equation (after solving forward and assuming non-explosive expectations) $M_{t} /\left(P_{t} C_{t}\right)=\exp \left(\psi_{t}\right)$, where $\exp \left(\psi_{t}\right)=\sum_{s=0}^{\infty} \beta^{s} \mathrm{E}_{t} \theta_{t+s}$. (This corresponds to eq. 16 in Bénassy (1995), but with a stochastic $\theta_{t}$ ). In logs, we have $m_{t}-p_{t}-c_{t}=\psi_{t}$.

Log employment with a Cobb-Douglas production function satisfies $h_{t}=p_{t}+y_{t}-w_{t}$ plus a constant (equate the marginal product of labour with the real wage to see this). In equilibrium $C_{t}$ is proportional to $Y_{t}$ and the money demand equation holds, so we can write this as $h_{t}=m_{t}-\psi_{t}-w_{t}$. Set $w_{t}$ such that $\mathrm{E}_{t-1} h_{t}$ is a constant (at the Walrasian level) to get $w_{t}=\mathrm{E}_{t-1}\left(m_{t}-\psi_{t}\right)$. Combining gives $h_{t}=\left(m_{t}-\mathrm{E}_{t-1} m_{t}\right)-\left(\psi_{t}-\mathrm{E}_{t-1} \psi_{t}\right)$ plus a constant. (This corresponds to eq. 32 in Bénassy (1995), but with a money demand shifter).

The production function gives $y_{t}=z_{t}+\alpha k_{t}+(1-\alpha) h_{t}$. Taking logs of the capital accumulation equation and using the fact that, in equilibrium, $I_{t-1}$ is proportional to $Y_{t-1}$ gives $k_{t}=(1-\delta) k_{t-1}+\delta y_{t-1}$ plus a constant. Combining gives $y_{t}=z_{t}+\alpha(1-$ $\delta) k_{t-1}+\alpha \delta y_{t-1}+(1-\alpha) h_{t}$. To substitute for $k_{t-1}$ use the production function to see that $y_{t-1}-z_{t-1}-(1-\alpha) h_{t-1}=\alpha k_{t-1}$. Combine and use the $\operatorname{AR}(1)$ process for $z_{t}$ to get $y_{t}=(\rho+\delta-1) z_{t-1}+(1-\delta+\alpha \delta) y_{t-1}-(1-\alpha)(1-\delta) h_{t-1}+(1-\alpha) h_{t}+\varepsilon_{t}$.

To derive (20), we minimise the loss function $\lambda \operatorname{Var}\left(y_{t}-\mathrm{E}_{t-1}\right)+(1-\lambda) \operatorname{Var}\left(\pi_{t}-\right.$ $\mathrm{E}_{t-1} \pi_{t}$ ). Notice from (12) and (13) and the policy rule $u_{t}^{m}=v \varepsilon_{t}$ (assuming no money demand shocks) that $\operatorname{Var}\left(y_{t}-\mathrm{E}_{t-1} y_{t}\right)=[(1-\alpha) v+1]^{2} \sigma_{\varepsilon}^{2}$ and $\operatorname{Var}\left(\pi_{t}-\mathrm{E}_{t-1} \pi_{t}\right)=$ $(\alpha \nu-1)^{2} \sigma_{\varepsilon}^{2}$. Differentiating with respect to $\nu$ and solving gives (20).

Similarly, minimising the loss function $\lambda \operatorname{Var}\left(y_{t}\right)+(1-\lambda) \operatorname{Var}\left(\pi_{t}-\mathrm{E}_{t-1} \pi_{t}\right)$ gives the first order condition $\lambda \partial \operatorname{Var}\left(y_{t}\right) / \partial v+(1-\lambda) \partial \operatorname{Var}\left(\pi_{t}-\mathrm{E}_{t-1} \pi_{t}\right) / \partial v=0$. The expressions for $\operatorname{Var}\left(\pi_{t}-\mathrm{E}_{t-1} \pi_{t}\right) / \partial v$ is as above and the (messy expression for) $\partial \operatorname{Var}\left(y_{t}\right) / \partial v$ is given in Söderlind (2003). Straightforward (but tedious) calculations show that the optimal policy coefficient is

$v=\frac{-\left(\alpha^{2}+\alpha-1+2 / \delta\right) \delta \lambda+((\alpha-1) \delta+2)\left(\alpha+(\lambda-1) \delta \alpha^{2} \rho+(1-\delta)(\lambda-\alpha) \rho\right)}{\left\{\left(\delta+\alpha^{3} \delta+\alpha^{2} \delta-3 \alpha \delta+4 \alpha-2\right) \lambda-\alpha^{2}[(\alpha-1) \delta+2]\right\}[(\alpha-1) \delta \rho+\rho-1]}$. 


\section{B Asset Pricing Appendix}

All expressions here are based on the first order condition (21). With a normal distribution, (21) can be evaluated as $\beta \mathrm{E}_{t} \exp (-\Delta c+r)$ which equals $\beta \exp [-\mathrm{E} \Delta c+$ $\mathrm{E} r+\operatorname{Var}(\Delta c) / 2+\operatorname{Var}(r) / 2-\operatorname{Cov}(\Delta c, r)]$. For a riskfree asset, the corresponding expression is $\beta R_{f} \exp [\mathrm{E} \Delta c+\operatorname{Var}(\Delta c) / 2]$. Divide to get $1=\exp [\mathrm{E} r+\operatorname{Var}(r) / 2-$ $\operatorname{Cov}(\Delta c, r)]$ and notice that $\mathrm{E}_{t} R_{t+1}=\exp [\mathrm{E} r+\operatorname{Var}(r) / 2]$. Together, this gives $1=$ $\mathrm{E}_{t} R_{t+1} \exp [-\operatorname{Cov}(\Delta c, r)] / R_{f}$. Take logs to get (21).

To derive (28) for an infinite consumption stream, let $B_{t}^{(1)}$ be the price of a claim on $C_{t+1}$. Use $R_{t+1}=C_{t+1} / B_{t}^{(1)}$ in (21) to find that $B_{t}^{(1)}=\beta C_{t}$. Now, if we buy (in $t$ ) a claim on consumption in $t+2$, then in $t+1$ we own a one-period claim which has the price $B_{t+1}^{(1)}=\beta C_{t+1}$. If the price in $t$ of this asset is $B_{t}^{(2)}$, then the return is $R_{t+1}=$ $B_{t+1}^{(1)} / B_{t}^{(2)}=\beta C_{t+1} / B_{t}^{(2)}$. Use in (21) to find that $B_{t}^{(2)}=\beta^{2} C_{t}$. Claims on further periods are priced analogously $\left(B_{t}^{(k)}=\beta^{k} C_{t}\right)$. Summing over all maturities $(1,2, \ldots)$ gives the price on a claim on the (infinite) future consumption stream as $B_{t}^{(\infty)}=C_{t} \beta /(1-$ $\beta$ ). The return of this infinitely lived consumption is $R_{t+1}=\left(C_{t+1}+B_{t+1}^{(\infty)}\right) / B_{t}^{(\infty)}$, which equals $C_{t+1} /\left(C_{t} \beta\right)$. The log return will therefore have the same risk premium as (28).

To calculate (34), notice that the covariance can be calculated as

$$
\operatorname{Cov}_{t}\left(\Delta c_{t+1}, \Delta c_{t+2}\right)=\operatorname{Cov}_{t}\left(c_{t+1}, c_{t+2}\right)-\operatorname{Var}_{t}\left(c_{t+1}\right)
$$

With only demand shocks and passive policy, (12) and (8) directly gives that $\operatorname{Var}_{t}\left(c_{t+1}\right)$ is the same as in (29). Similarly, $\operatorname{Cov}_{t}\left(c_{t+1}, c_{t+2}\right)$ is $(1-\delta+\delta \alpha) \operatorname{Var}_{t}\left(c_{t+1}\right)-(1-\alpha)^{2}(1-$ $\delta) \sigma_{\psi}^{2}$. Combining gives (34).

To calculate (35), notice that $\operatorname{Var}_{t}\left(c_{t+1}\right)$ is now the same as in (30), while (12), (8) and (14) give that $\operatorname{Cov}_{t}\left(c_{t+1}, c_{t+2}\right)$ is $\left[\frac{\delta \alpha+\rho+\delta \alpha(1-\alpha) v}{(1-\alpha) v+1}\right] \operatorname{Var}_{t}\left(c_{t+1}\right)$. Combining gives (35).

To calculate (36), notice the following. By using the first order condition (21) and the fact that all second moments are constant, it is straightforward to find that the real interest rate is (constant suppressed) $r_{f t}=\mathrm{E}_{t} \Delta c_{t+1}$, and that a two-period real interest rate is (constant suppressed) $r_{f t}^{(2)}=\mathrm{E}_{t}\left(c_{t+2}-c_{t}\right) / 2$. From the previous analysis we already know that the consumption claim has a $\log$ price equal to $c_{t}$. Combining with (12), (8) and (14) gives (36). 


\section{References}

Andersen, T. G., T. Bollerslev, F. X. Diebold, and C. Vega, 2007, "Real-time price discovery in stock, bond and foreign exchange markets," Journal of International Economics, forthcoming, 73, 251-277.

Bakshi, G. S., and Z. Chen, 1996, "Inflation, asset prices, and the term structure of interest rates in monetary economies," The Review of Financial Studies, 9, 241-275.

Bénassy, J.-P., 1995, "Money and wage contracts in an optimizing model of the business cycle," Journal of Monetary Economics, 35, 303-315.

Boyle, G. W., and J. D. Peterson, 1995, "Monetary policy, aggregate uncertainty, and the stock market," Journal of Money, Credit, and Banking, 27, 570-582.

Buraschi, A., and A. Jiltsov, 2005, "Inflation risk premia and the expectations hypothesis," Journal of Financial Economics, 75, 429-490.

Cooley, T. F., and E. C. Prescott, 1995, "Economic growth and business cycles," in Thomas F. Cooley (ed.), Frontiers of business cycle research, Princeton University Press, Princeton, New Jersey.

Hansen, L. P., and R. Jagannathan, 1991, "Implications of security market data for models of dynamic economies," Journal of Political Economy, 99, 225-262.

Hercowitz, Z., and M. Sampson, 1991, "Output, growth, the real wage, and employment fluctuations," American Economic Review, 81, 1215-1237.

Sellin, P., 2001, "Monetary policy and the stock market: theory and empirical evidence," Journal of Economic Surveys, 15, 491-541.

Söderlind, P., 2003, "Monetary policy and bond option pricing in an analytical RBC model," Journal of Economics and Business, 55, 321-330.

Thorbecke, W., 1997, "On stock market returns and monetary policy," The Journal of Finance, 52, 635-654.

West, K. D., 1986, “Targeting nominal income: a note,” Economic Journal, 96, 10771083. 
Woodford, M., 2002, Interest and prices: foundations of a theory of monetary policy, manuscript prepared for Princeton University Press. 